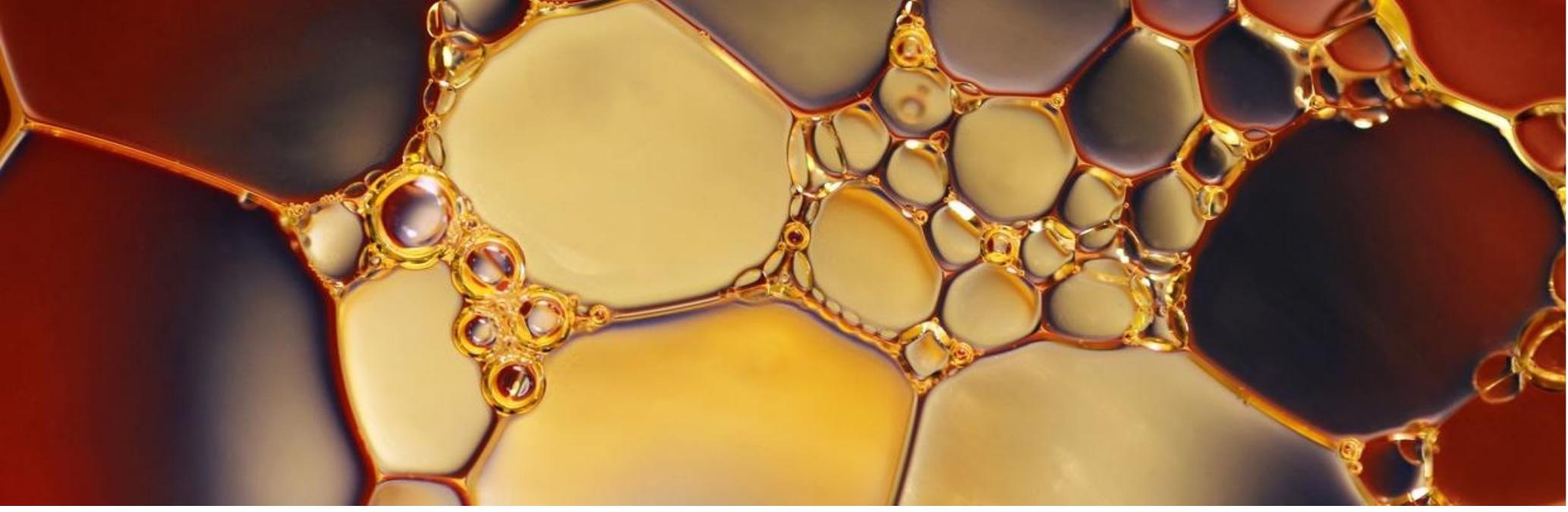

\title{
Why the biomedical Sciences need Philosophy: theoretical and practical Reasons illustrated with examples from the BioThera Institute of Philosophy
}

\author{
Authors: $\quad$ Alahí Bianchini, Ignacio Mastroleo \\ Submitted: 24. December 2020 \\ Published: $\quad$ 25. January 2021 \\ Volume: 8 \\ Issue: 1 \\ Affiliation: National Scientific and Technical Research Council (CONICET), \\ BioThera Research Institute for the Philosophy of Translational \\ Medicine, FLACSO collaborating centre of PAHO/WHO, Buenos \\ Aires, Argentina \\ Languages: English \\ Keywords: $\quad$ Bioethics, research ethics, public health emergency, science \\ Categories: Humanities, Social Sciences and Law \\ DOI: $\quad$ 10.17160/josha.8.1.728
}

Abstract:

The biomedical sciences need philosophy on at least two levels. Firstly, we can find strong arguments that recognize the need for philosophy on a theoretical level, such as the development of scientific theories that in turn can have effects such as the development of new treatments or other medical interventions. However, philosophy, and particularly bioethics, is necessary for the biomedical sciences at the practical level, that is, in the daily practice of science and the achievement of its goals and results. In this work, we will reconstruct some of the arguments that point out the importance of philosophy for science on a theoretical level, and, furthermore, we will argue that these same conceptual tools of philosophy can be useful on a practical level of biomedical sciences too. To this end, we will present four cases from the concentual recearch conducted hy the BinThera Inctitute of Philosonhyv the enhanced definition of medical

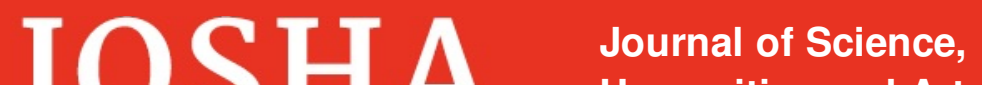 Humanities and Arts




\title{
Why the biomedical sciences need philosophy: theoretical and practical reasons illustrated with examples from the BioThera Institute of Philosophy
}

\author{
Alahí Bianchini ${ }^{1,2}$, Ignacio Mastroleo 2,3,*
}

1. "Ambrosio L. Gioja", Institute of Legal and Social Research, University of Buenos Aires (UBA).

2. Program of Bioethics, Facultad Latinoamericana de Ciencias Sociales (FLACSO)

3. National Scientific and Technical Research Council (CONICET)

* Corresponding author: ignaciomastro@gmail.com

Key words: bioethics, research ethics, public health emergency, science

\section{Abstract}

The biomedical sciences need philosophy on at least two levels. Firstly, we can find strong arguments that recognize the need for philosophy on a theoretical level, such as the development of scientific theories that in turn can have effects such as the development of new treatments or other medical interventions. However, philosophy, and particularly bioethics, is necessary for the biomedical sciences at the practical level, that is, in the daily practice of science and the achievement of its goals and results. In this work, we will reconstruct some of the arguments that point out the importance of philosophy for science on a theoretical level, and, furthermore, we will argue that these same conceptual tools of philosophy can be useful on a practical level of biomedical sciences too. To this end, we will present four cases from the conceptual research conducted by the BioThera Institute of Philosophy: the enhanced definition of medical innovation as a new non-validated practice, the ethical justification of the duty of States to promote clinical research, the fair play model for the distribution of fair 
benefits in clinical research, and the ethical model for allocation of extremely scarce resources in times of public health emergency.

\section{Theoretical reasons why science needs philosophy}

In their article "Why science needs philosophy" (Laplane et al, 2019), the authors explore four ways in which philosophy can impact science at the theoretical level: the clarification of scientific concepts, the critical evaluation of scientific assumptions or methods, the formulation of new concepts and theories, and the promotion of dialogue between different sciences and scientific theories, as well as between science and society.

To prove this hypothesis, they appeal to three examples. First, the importance of conceptual clarification can be clarified in the example of the definition of stem cells, and in particular "stemness," the property that defines stem cells. According to the authors, this application is relevant for the analysis of scientific terms, but also because it allows the creation of new theoretical frameworks, which leads to new experimental research, and, hopefully, to new applications such as drugs and vaccines.

In the case of stem cells ("stemness"), conceptual clarification is embodied in the distinction between four kinds of properties: a categorical property (an intrinsic property of the stem cell, independent of its environment), a dispositional property (an intrinsic property of the stem cell that is controlled by the microenvironment), a relational property (an extrinsic property that can be conferred on non-stem cells by the microenvironment), or a systemic property (a property that is maintained and controlled at the level of the entire cell population). This distinction implies different types of therapies, for example in the case of cancer stem cells in oncology.

Another necessary aspect of philosophy for science is the critical evaluation of scientific assumptions, which the authors exemplify through immunogenicity and 
the concept of the microbiome. A philosophical critique of the theoretical framework of autoimmunity led, for example, to the theory of the discontinuity of immunity, which, in the authors' words, sheds light on many important immunological phenomena, including autoimmune diseases, immune responses to tumors, among others.

The authors also highlight the influence of philosophy in the formulation of new concepts and theories. An example concerning this is represented in the study of cognition and cognitive neuroscience. Specifically, Jerry Fodor's theory of the modularity of mind, which postulates that mental phenomena arise from the functioning of multiple processes, not just one undifferentiated one, marked a milestone in the psychology of cognitive development. In this sense, another contribution of philosophy is the provision of conceptual tools applied to the engineering of artificial intelligence, to the construction of psychological theories of the variables of mental state, and the use of neuroscience tools to investigate consciousness.

In short, the main thesis of the Laplane et al. 2019 is that philosophers can use logic, conceptual analysis, and rigorous argumentation in a much more thorough way than scientists, since it is not their daytime or main activity, and they can use it to apply these tools in scientific theory. 


\section{Practical reasons why science needs philosophy: extending the argument}

Our aim in this section is to extend this thesis and to argue that not only these conceptual tools of philosophy can be used to the benefit of scientific biomedical theories but also that they that have useful consequences in the context of the day-to-day aspects of the practice of the biomedical sciences, particularly in clinical research and health care. To this end, we will present four cases from the conceptual research conducted by BioThera Institute of Philosophy: (1) the enhanced definition of medical innovation as new non-validated practice, (2) the ethical justification of the duty of States to promote clinical research, (3) the fair play model for distribution of fair benefits in clinical research, and (4) the ethical model for allocation of extremely scarce resources in times of public health emergency.

For those unaware of the Biothera Philosophy Institute work, a brief introduction may be useful. The BioThera Research Institute for Philosophy of Translational Medicine -in short, BioThera Institute of Philosophy (BIP)- main aim is to develop conceptual and empirical research. Taking advantage of the solid research lines and academic backgrounds of its current researchers, BIP is focused on the philosophy of translational medicine and bioethics. This research is potentially of great practical importance in education, regulatory policies, and ethical issues in professional practice for those working in biomedical sciences. However, BIP's wider goal is to foster human flourishing and well-being through the creative and responsible use of philosophy and scientific research in different fields, such as law, social and political sciences, economy, etc. 


\section{Innovation in medicine as a new non-validated practice}

Firstly, Mastroleo and Holzer (2020) through an original conceptual analysis show how the definition of innovation in medicine can be improved, understanding it as a new non-validated practice and distinguishing it from biomedical research. In a normal context, the need for a sound concept of innovation in medicine usually arises with the use of unproven interventions outside research in patients with severe disease and without reasonable alternatives. In public health emergency contexts, the need to distinguish these biomedical activities came to light during the current COVID-19 pandemic with the "compassionate use" (outside of research) of drugs such as hydroxychloroquine, ivermectin or, convalescent plasma which were not always used responsibly and may have interfered inappropriately with biomedical research. In both contexts, the main questions that arise are two. First, if it is ethically permissible to use unproven interventions. Second, if this is the case, what are the ethical criteria and responsibilities of the different parties involved. The conceptual work done by the researchers of the BioThera Institute of Philosophy has already been applied to both public health emergency and regular contexts. On the one hand, the definition of new-non validated practice has been instrumental in revising the World Health Organization's current ethical framework on an emergency exceptional use of unproven non-research interventions (a case of new non-validated practice in public health emergencies) (Mastroleo et al. 2020, WHO 2020). On the other, it also has served to the ethics of the use of new and insufficient validated medical practices (new non-validated practice) in the domain of Alzheimer's disease (Daly et al. 2020). This work shows how philosophy is necessary for the clarification of ethical concepts that are used to regulate biomedical sciences, in this case, health care and clinical research. 


\section{Duty to research}

Second, the BioThera Institute of Philosophy has also worked during the pandemic to clarify the moral duty of States to encourage clinical research and ensure its responsible character (Bianchini, 2020), which is diffused in various documents of international health agencies. This duty also involves special obligations, so it is necessary to specify its characteristics, content, and theoretical basis for why it is a duty, who are the agents obliged to the duty to research, who are the beneficiary parties, how this duty is justified, among other questions that remain unanswered. Although determining what is the duty to research and its content is certainly a multidisciplinary work, the conceptual tools needed are distinctly developed by the philosophy of law and political philosophy. In turn, this work shows how philosophy is necessary for the clarification of ethical concepts that are used to regulate biomedical sciences.

\section{Fair play model}

Third, another example of BioThera Institute of Philosophy collaboration in biomedical research is the original development of the fair play model that addresses equitable benefits in clinical research to host communities. With the fair play model, Holzer (2020) builds a normative basis for the equity obligations assumed by researchers and sponsors that are due to the host communities. In the proposed model, the idea is postulated that communities are exploited when they do not benefit sufficiently from the production of socially valuable knowledge. In other words, a possible approach to what is known as fair benefit-sharing is justified in the field of research ethics. The philosophical work here is to stipulate criteria that 
determine how the distribution of burdens and benefits should be regulated. This clarifies the obligations of justice for biomedical researchers, which has the effect of helping to reduce the ethical, regulatory, and legal risk that these researchers and their institutions often run when they conduct research in low- or middle-income countries or contexts. In turn, some of the insights of this original equity conceptual model for biomedical research developed by the BioThera Institute of Philosophy are being applied during the pandemic to analyze and monitor the equitable distribution of COVID-19 vaccines through COVAX, the vaccines pillar of the ACT-Accelerator, convened by CEPI GAVI and WHO, that aims to accelerate the development and manufacture of COVID-19 vaccines, and to guarantee fair and equitable access for every country in the world (WHO 2020). In our view, this can be regarded as an example of the formulation of new models of justice and fairness that may have an impact on clinical trial research regulation at a global level.

\section{Ethics of allocation of extremely scarce resources}

Finally, we want to introduce our work on the allocation of extremely scarce resources during public health emergencies in Argentina (Rivera López et al, 2020) as an alternative model of fair allocation from the other major model presented in Argentina (Maglio et al., 2020). In times of pandemics such as that currently caused by Sars-CoV-2, there may be extreme shortages of resources such as respirators or essential medical supplies. This situation requires the adoption of a criterion of justice through which the resources are allocated equitably, both at the time of triage and at the time of playoff between two people. Some of the criteria analyzed in the article were prioritization by age, reciprocity, and instrumentalization, among others. Beyond its practical implementation, this is a clear example of the necessity of applied ethics for the promotion of dialogue between biomedical sciences and society. 


\section{Conclusions}

One of the reasons why we maintain that philosophy is the discipline that should deal with these normative practical issues of biomedical sciences is, in the first place, because it deals with the validity of the practical arguments that justify the background governance institutions regulating biomedical sciences education, research and practice. The main thesis of Laplane et al. 2019 is that philosophers can use logic, conceptual analysis and rigorous argumentation in a much more thorough way than scientists, since it is not their main activity, and they can use it to apply these tools in scientific theory. The same argument can be extended to the governance institutions regulating biomedical sciences. For example, by providing an overview of different models of what is fair, it is possible to think which of these applies best to a new specific topic of biomedical science or when a new regulatory and governance approach is needed. Finally, a good practical decision is better when it also has a solid foundation since a sound normative ethical theory sufficiently abstract will also serve as a basis to allow thinking beyond the specific cases.

Moreover, we agree with Laplane et al. (2019) that there are other good reasons why science needs philosophy, such as the more efficient distribution of intellectual labor, and that this can be enhanced when philosophy researchers integrate interdisciplinary teams. In turn, we also agree with Laplane et al. (2019) that this interdisciplinary work between science and philosophy is beneficial for both sides and that it should be foster. In the case of practical philosophy and bioethics, close work with biomedical sciences had an impact on the development of research methodology, namely, the positive effect of moving philosophers from the "ivory tower" individual model of production to the collaborative model of production 
proper of biomedical sciences. In turn, more interdisciplinary collaboration has the potential to create a more productive and resilient scientific community for democratic societies (Bianchini et al. 2020).

\section{Conflicts of interest and acknowledgments}

Alahí Bianchini (researcher) and Ignacio Mastroleo (director) are members of the BioThera Institute of Philosophy. We are extremely grateful to Felicitas Holzer and Roland Mertelsmann for their valuable comments and suggestions.

\section{Institutional Support}

Work on this paper was supported by The National Research Council of Argentina (CONICET), UBACyT 20020150100193BA (Principle of autonomy, popular sovereignty, and theory of democracy) from the University of Buenos Aires and the BioThera Research Institute for Philosophy of Translational Medicine (BioThera Foundation Grant 2019-2021). The views expressed in this paper are personal and do not necessarily reflect the policies of the institutions mentioned above. 


\section{References}

Bianchini, A. (2020). Deber estatal de investigar y ley nacional de investigación biomédica en Argentina: Una justificación ética. Revista de Derecho y Bioética, pre-print https://doi.org/10.5281/zenodo.4106630

Bianchini, A., Eduardo Rivera López, Florencia Luna, Marcelo Alegre, Diana Pérez, \& Ignacio Mastroleo. (2020). Algunas cuestiones éticas a propósito de la pandemia de Covid-19. Ciencia Hoy, 29(170), 15-19. https://doi.org/10.5281/zenodo.3974587

Daly, T., Mastroleo, I., Gorski, D., \& Epelbaum, S. (2020). The ethics of innovation for Alzheimer's disease: The risk of overstating evidence in the case of "metabolic enhancement" protocols. Theoretical Medicine and Bioethics. In press.

Holzer, F. (2020). Treating host communities fairly in international health research. Sorbonne Université.

Laplane, L., Mantovani, P., Adolphs, R., Chang, H., Mantovani, A., McFall-Ngai, M., Rovelli, C., Sober, E., \& Pradeu, T. (2019). Opinion: Why science needs philosophy. Proceedings of the National Academy of Sciences, 116(10), 3948-3952. https://doi.org/10.1073/pnas.1900357116

Maglio, I., Valdez, P., Cámera, L., Finn, B., Klein, M., Pincemin, I., Ferraro, H., Galvalisi, N., Alessandrini, G., Manera, J., Musacchio, H., Contreras, P., Garea, M., Lüthy, V., Nemerovsky, J., Baldomá, F., Cherro, A., Ranzuglia, L., Malfante, P., ... García, A. (2020). Guías éticas para la atención durante la pandemia covid-19. Recomendaciones multisocietarias para asignación de recursos. Medicina (Buenos Aires), 80(Supl. III), 45-64. https://www.medicinabuenosaires.com/indices-de-2020/volumen-80-ano-2020-s-3-indice/guias eticas/

Mastroleo, I., \& Holzer, F. (2020). New non-validated practice: An enhanced definition of innovative practice for medicine. Law, Innovation and Technology, 12(2), 318-346. https://doi.org/10.1080/17579961.2020.1815405

Rivera López, E., Abal, F., Rekers, R., Holzer, F., Melamed, I., Salmún, D., Belli, L., Terlizzi, S., Alegre, M., Bianchini, A., \& Mastroleo, I. (2020). Propuesta para la elaboración de un protocolo de triaje en el contexto de la pandemia de COVID-19. Revista de Bioética y Derecho, 3(50), 37-61. https://doi.org/10.1344/rbd2020.50.31816

World Health Organization (WHO). (2020, September 9). Fair allocation mechanism for COVID-19 vaccines through the COVAX Facility. https://www.who.int/publications/m/item/fair-allocation-mechanism-for-covid-19-vaccines-through-the-covax-f acility 


\section{About the Author:}

Alahí Bianchini is a Ph.D. student in Philosophy at the University of Buenos Aires. She works on research ethics and political philosophy. Currently, the subject of her dissertation is on the moral duty of States to encourage clinical research and ensure its ethical character.

Dr Ignacio Mastroleo works on research ethics, medical ethics and theories of justice. His current lines of inquiry include ethics of innovative medical practice, ethics of emergency use of unproven interventions and post-trial responsibilities. 